\title{
Retórica colonial: el otro Lingüístico
}

\author{
Manuel José BOTERO CAMACHO \\ Universidad Complutense de Madrid
}

\section{RESUMEN}

A lo largo de esta reflexión intentaré introducir al lector dentro de la realidad literaria que suponen tres textos escritos en los albores de lo que hoy se reconoce como la nación colombiana: Elegías de varones ilustres de Indias de Juan de Castellanos, Noticias Historiales de Fray Pedro Simón, y El Carnero de Juan Rodríguez Freile. Esta realidad es el motor de las acciones que el hombre europeo desempeñó en el Nuevo Mundo; casi como textos sagrados se convirtieron en justificación, y, más que eso, en profunda creencia. Es de allí que surge la idea de un otro que hasta hoy atraviesa el imaginario colectivo. Un otro bárbaro, cargado de oro y súbdito del demonio, un otro que no caminó por América pero que sin duda transitó por Europa y cuya idea manchó de sangre la tierra del Nuevo Mundo.

Palabras clave: el otro, cronistas, alteridad, las Indias, indígenas.

\section{Colonial Discourse: the Lingual Other}

\begin{abstract}
Throughout this essay I'll try to introduce the reader in the literary reality that is supposed by three book written in the dawn of what today is known as Colombia.: : Elegias de varones ilustres de Indias written by Juan de Castellanos, Noticias Historiales by Fray Pedro Simón and El Carnero by Juan Rodríguez Freile. This reality is the engine of the behavior portrayed by the european man in the Americas; almost as if they were sacred, or holy, texts, they became belief. The idea of other, that until today wanders in our imagination. A barbaric other, loaded with gold and minion of the devil, an other that didn't walked in America but most definitely roamed through Europe and whose idea stained the New World's land with blood.
\end{abstract}

Keywords: The other, chronicles, otherness, West Indies, Indians.

SUMARIO: 1. A manera de introducción: el otro y el monstruo. 2. ¿Ilustres? Juan De Castellanos. 3. Noticias del Bárbaro Colonial. Fray Pedro Simón. 4. El otro visto desde la otredad: Juan Rodríguez Freile. 5. El otro como figura del poder. Yurupari. 6. A manera de epílogo: de lo mágico a lo maravilloso. 7. Bibliografía. 


\section{A manera de introducción: el otro y el monstruo}

Parece que éste fue consejo del diablo por llevarse todos aquellos y quitarnos el oro... Juan Rodríguez Freile

Para poder comenzar a hablar de lo que lo otro o el otro significan en América, o mejor, en Europa con respecto de América, es necesario referirse a lo monstruoso. Aunque pueda parecer agresiva esta comparación, es importante recordar que la noción del otro como igual es muy reciente en la historia occidental. Es una doctrina derivada de la retórica de los derechos humanos y su aplicación a las políticas efectivas es más bien contemporánea. Desde el punto de vista formal puede verse expresada esta nueva idea de lo otro en el pensamiento del antifascista Norberto Bobbio a mediados del siglo XX. Desde el punto de vista religioso el cambio es tardío. Aunque las puertas de esta unión de la diferencia, se empiezan a vislumbrar en el Concilio Vaticano II, presidido por el Papa Juan XXIII, es sólo hasta Juan Pablo II que se formaliza: en su afán ecuménico, convoca a todos los líderes religiosos (de todas las religiones) y los llama hermanos. Es hasta el siglo XX que la diversidad es considerada como valor incluso por encima de lo que es estable, clásico y considerado legítimo en sí mismo.

Antes de eso, sin embargo, lo otro, lo ajeno, lo extraño, está asociado con el miedo. En primer lugar miedo a que desestabilice lo estable, en segundo lugar a que sustituya lo conocido. La clasificación general que los griegos y los romanos dieron a los extranjeros fue la de bárbaros. Eran pueblos distintos a aquellos que así los nombraban; pero eran también distintos entre sí: no pude pensarse en nada más dispar que un celta y un tártaro, un persa y un vikingo. Eran temibles, ignorantes, más cercanos a las bestias que a los hombres. Es una lástima que no hubieran dejado, estas tribus, testimonios escritos, pues quienes escribieron, desde el desconocimiento y el extrañamiento, lo hicieron bajo el influjo del miedo. Una vez descompuesto el Imperio, las ciudades se envuelven sobre sí mismas cortando casi por completo la comunicación entre ellas. Las leyendas bárbaras se funden con las propias y las tímidas identidades nacionales empiezan a germinar a la sombra del bosque, de lo oscuro, lo desconocido: el miedo. Desde los salteadores de caminos hasta las brujas, duendes y ogros, incluso el fabuloso lobo, asechan en el umbral de las ciudades, que se protegen a la luz de los ayuntamientos y las parroquias, de lo otro de los otros, que han quedado convenientemente fuera de los muros.

Las cruzadas serán la cumbre de la unión entre estado e Iglesia para eliminar al otro. El viaje a la cuna del Islam que por un instante unió a la ya quebrantada Iglesia (ortodoxos y romanos), que oficialmente tiene una razones religiosas y que luego la historia ha revelado otras económicas, tiene también su fundamento en el miedo: el miedo de la Iglesia griega que ve a los musulmanes llegar a las puertas de Edesa, el miedo de los franceses que ven a los moros al pie de los pirineos. En esta guerra de de tantas guerras los templarios fueron protagonistas de un escándalo sin precedentes. Verdad o mentira, las acusaciones más graves en su contra, derivaban de la profunda 
empatía que habían establecido con el pueblo islámico. Los templarios fueron señalados por fraternizar con el otro, al punto de respetarlos, de aprender de sus habilidades, técnicas y ciencias e, incluso, de compartir algunas de sus creencias. Lo otro siempre ha sido causa de temor.

Regresando al tema que me ocupa, a finales del siglo XV, Francisco de Vitoria, hablará de la igualdad formal del indio americano: un ser igual en forma, pero no del todo en espíritu. Esto es, el indio tiene, dentro de sus posibilidades, ser igual y dejar su otredad. El indio es susceptible de ser igual. Un poco sobre las mismas líneas que deja san Pablo en su carta a los Romanos (líneas que al parecer olvida Juan Pablo II). A pesar de ser el apóstol de los gentiles, de los otros, san Pablo les recuerda que sólo somos hermanos en Cristo. Mientras tanto, el indio no converso será incompleto.

Las opiniones referidas al monstruo expuestas por Aristóteles en la Generación de los animales, constituyen el punto de partida de aproximación al monstruo desde la baja Antigüedad hasta los cronistas de Indias. En su tratado sobre el origen de los indios, Gregorio García se remite a Aristóteles para afirmar que "el principio de los monstruos consiste en no alcanzar naturaleza su perfecto fin, que es engendrar cada uno su semejante, porque no alcanzándole, es monstruo lo que se engendra, según aquella parte en que se diferencia de su principio". Así pues, a partir de Aristóteles, desde el aspecto genético, el monstruo es no similitud. (Cabarcas: 51)

Por otra parte, San Agustín quiso aligerar la diferencia proponiendo que si todo está creado por Dios, y en Dios no hay imperfección, Dios no creará nada incompleto. Por tanto, lo monstruoso debe ser hermoso en alguna medida, y es la propia limitación del hombre lo que no le permite apreciarlo. Esto, tal vez, justifique las primeras impresiones de los conquistadores al pensar que habían alcanzado el Edén. No obstante, muy rápidamente esta concepción se desvanece convirtiendo a esto seres en monstruos puesto que no encontraron identidad con ellos.

Al reseñar la sensación experimentada por los viajeros medievales de estar penetrando en otro mundo, Claude Kappler afirma que se puede pensar que el sentido de la expresión alter, en el decadente latín medieval, designa el otro, no entre varios posibles sino como oposición nominal de dos cosas: alter 'es lo que no soy yo'. Alter mundus es, en la perspectiva de dos únicos mundos posibles, el nuestro y el de 'los otros', vale decir, el contrario del nuestro. Estas concepciones influirán largamente en la vida cultural de Occidente y también acompañarán a los descubridores del siglo XVI en su búsqueda de asimilación de las realidades que van explorando. (Cabarcas: 41-42)

Si lo otro es no similitud, y el monstruo es no similitud, entonces el otro, por definición queda incluido dentro de lo monstruoso. Esto da carta blanca al español para eliminarlo. Se convierte en instrumento de la divinidad al aniquilar todo aquello que no puede llegar a la perfección, al ser. Todo aquello que no participa del ser, no es, y lo que no es no puede existir. 
Faltaban las palabras para referirse a la realidad encontrada; pero puede decirse que en la concepción medieval del mundo, de la que muchos descubridores y conquistadores eran portadores, lo que no existe es lo no escrito en los libros. (Cabarcas: 43)

El lenguaje, al igual que había sucedido con los griegos y los romanos, se vuelve definitivo para afianzar la diferencia. Se comete una petición de principio puesto que como son diferentes no tienen el mismo lenguaje y como no tienen el mismo lenguaje son diferentes. Los indios existían, estaban ahí para probarlo, por lo tanto tenían que estar descritos en alguna parte. Es a esa tradición de la autoridad a la que están suscritos los españoles; algún autor tenía que haberlos referidos pues en lo escrito estaba la verdad. Entonces pasa lo increíble: es la realidad la que debe acoplarse a los textos y no los textos a la realidad.

es probable establecer que el mundo americano descrito por los cronistas será su testimonio de realidad y de verdad, a pesar que para ellos conocer será, en buena medida, reconocer lo que su cultura, religiosa y literaria, da como existente. (Cabarcas: 43-44)

\section{¿Ilustres? Juan De Castellanos}

Voy a remontarme a los orígenes, y el principio es Castellanos, son las Elegías. Es desde este momento que la visión del nativo heredada de Colón, empieza a matizarse, puesto que Castellanos le procura profundidad, perspectiva. Perspectiva es una palabra que podría utilizarse para comenzar a entablar esta reflexión sobre la imagen que Castellanos construye del nativo americano. En las Elegías se inaugura, por primera vez en un contexto americano, la figura del otro. Se define al nativo de múltiples maneras, lo importante de esto, es la existencia de una definición que va más allá de una nueva descripción "natural". Hasta ahora (siglo XVI) las descripciones de los nativos americanos, parecían incluirlos más bien en las imágenes de los bestiarios medievales considerándolos un renglón más dentro del reino animal.

Cuando Castellanos describe el encuentro entre occidente y las bautizadas Indias, nos presenta una serie de personajes que se diferencian de aquellos otros referidos en las primeras crónicas. Estos nativos tienen cuerpos humanos con toda la grandeza y la pureza del ser humano; en el canto cuarto se lee: "Donde se trata como hallaron tierra, y descubrieron la grandeza deste nuevo mundo" (Castellanos: 32). (Una de esas grandezas referidas son sus habitantes. No hay que olvidar el influjo de esa primera mirada de Colón sobre Juan de Castellanos).

La primera referencia que se hace trata de homologar esas figuras que se ven en la playa con el imaginario mitológico clásico: "Si son sátiros éstos, o silvanos, y ellas aquellas ninfas de Aristeo: o son faunos lascivos y lozanos, o las nereides, hijas de Nereo, o driades que llaman, o nayades." (Castellanos: 34). Inmediatamente después se establece toda esa comparación mitológica como una forma de encontrar adjetivos (desconocidos, por lo demás) para destruir a los nativos. De esa forma se introduce la alabanza de un otro inaprehensible. 
Ansí todas las ninfas como ellos son bien proporcionados y bien hechos, sacados son de hombros y de cuellos, y más pecan de anchos que de estrechos: ¡Cuán luenga hermosura de cabellos! ¡Qué gran tabla de espaldas y de pechos! (Castellanos: 34)

Esta visión contrasta con la descripción que hasta este momento se tenía de los nativos, pero a la vez se vuelve justificación del viaje de Colón por parte de Castellanos, visto como una empresa milagrosa; si, cómo Castellanos dice, Colón fue llevado de la mano de Dios, no pudo haberlo llevado a otro lugar que no fuera el Paraíso. Sin embargo, hay un subtexto, es imposible que éstos no-bautizados fueran parte del Reino Retórico de Dios; entonces se introduce la lascivia y la sensualidad que a la vez los vuelve más humanos pero menos salvos. La visión de estas criaturas esplendorosas tendrá que degenerar, inevitablemente, en una retórica del pecado, puesto que estos seres no podían, gratuitamente, ser mejores que los españoles.

Por cierto todos ellos son dispuestos, y ellas por consiguiente bien dispuestas; pero los trajes son muy deshonestos, aun para las mujeres deshonestas, pues los unos y otros andan prestos para solenizar venéreas fiestas [...] Pues no son en estado de inocencia, que hijos son de Adán y descendientes; (Castellanos: 34)

Esta última frase introduce al nativo en el mundo de los hombres, pero en el de los hombres de naturaleza caída. En este momento el hombre americano es visto como una suerte de adjetivo imposible; natural, extraño, desconocido. Pero a medida que el barco avanza y que los conquistadores se introducen en el territorio inhóspito de aquello que consideraban las Indias Orientales, este otro (salvaje), va adquiriendo características que lo emparentan con el pecado. ¿Contradicción? Es probable, pero lo cierto es que al acercarse a lo desconocido, los conquistadores atribuyen a los nativos expresiones exacerbadas provenientes de los referentes lingüísticos que conocen, imponiéndoles una nueva característica: la de monstruos.

Y por naturaleza proveídos hombres, en la cabeza, de dos caras [...] No mucho de los Andes apartado, de los pigmeos que la fama siembra captivaron un macho y una hembra [...] Salvaje más crecido que gigante, y cuyas proporciones y estatura eran según las pintan en Atlante, de hombre natural la compostura, en el hocico solo discrepante, algo largo y horrenda dentadura, el bello cuasi pardo, corto, claro, digo no ser espeso, sin raro. (Castellanos: 865-866)

Es claro que se trata de una transculturación de mitologías pero, sobre todo, de una imposición lingüística, pues algunos de estos monstruos son referidos por los guías de las expediciones, iqué son nativos! Los referentes con que se cuentan, a nivel lingüístico, son aquellos que utiliza la mitología clásica. Esto es importante porque por debajo de los referentes occidentales fluye el discurso nativo, esto es, se sitúa en un nivel equiparable al discurso blanco/culto del siglo XVI. Incluso existen partes en las Elegías en las que el discurso nativo no está filtrado por la palabra occidental, utilizando para sus octavas reales palabras extraídas de los dialectos locales. 
Atónitos al avistar, sorprendidos al introducirse en territorio y finalmente horrorizados ante la idea de ese otro como el peligro caníbal, los conquistadores construyen un tercer referente; un referente que a pesar de partir de un estudio natural, se convierte en la experiencia del temor y la justificación de la guerra. No hay sino que recordar el episodio de La Gaitana en donde la figura de la tortura y de la resistencia americana forman una antonimia: el hecho real, el acto mismo del canibalismo, sin importar su veracidad histórica sino la realidad en que se convierte el asunto entre Añasco y la Gaitana. No importa si sólo fue una guerra de resistencia "cruenta y aguerrida" o si efectivamente se trató "de un banquete caníbal". Lo que importa en realidad es la introducción de este concepto en la conciencia de la conquista que avala y autoriza el exterminio del otro.

El desarrollo del otro en la visión de Castellanos fluye paralelo al desarrollo de la mitología. En un principio lo clásico se impone sobre el otro. Más adelante los mitos del nativo son definidos como referentes nominales clásicos. Finalmente la mitología del otro se eleva desnuda de la tradición europea para sostenerse independientemente e introducirse de manera definitiva en el imaginario occidental. El mito de El Dorado es un claro ejemplo de esto, en donde el cuerpo de un hombre recubierto de oro hace que se confunda el hombre con el tesoro. Ficción o realidad, se convierte en el norte que guiará las brújulas de muchos hombres que, por codicia o aventura, regalarán su vida a ese sueño en que se convirtió América.

\section{Noticias del Bárbaro Colonial. Fray Pedro Simón}

En segundo lugar, se encuentra Fray Pedro Simón con sus Noticias Historiales. Se verá de una manera sorprendente, cómo los referentes de Castellanos son continuados, de alguna forma, en el texto de Simón. Es como si una vez aceptada la condición monstruosa del americano, se tomaran ciertos hechos y se transmitieran de manera espeluznante. Al tratarse de un texto bastante extenso tomaré como paradigma un episodio particular, el de la toma de Ibagué, para dar cuenta de este camino que la retórica le labra a los conquistadores hacia el interior del continente. Pero antes, basándome en el capítulo de Álvaro Félix Bolaños titulado "Canibalismo y retórica en la justificación del exterminio del Pijao", me aproximaré a la noción del hombre americano que circuló gracias a Simón.

La noción del otro es lo que define la obra de Fray Pedro Simón. Un otro que según Bolaños se construye con base en un imaginario que desde la antigüedad clásica, con los Griegos, se instauró como forma de nombrar lo desconocido. La pregunta surge cuando al enfrentarse a un texto netamente colonial Bolaños se interroga por "el verdadero sentido del ataque retórico de Simón”. ¿Cuál? La forma de nombrar a muchos de los nativos indígenas de manera desdeñosa y de compararlos con una bestialidad que sólo la imaginación Europea de más de quince siglos, fue capaz de construir para definir eso que no podía nombrar o, mejor, eso que le convenía no nombrar de un modo explícito. A grandes rasgos esta es la tesis central del texto "Canibalismo y retórica en la justificación del exterminio Pijao". El Pijao es el eje de toda una parte de la obra de Simón que él mismo confiesa "no ser suficiente" y de la que, sin embargo, se ocupa con tanto afán legitimador español como si fuera 
un intento, por medio de la palabra, de recurrir al artificio para el convencimiento del exterminio y la barbarie de los españoles.

Interrogarse por el otro como bárbaro, sodomita, sucio y pecador, asegura Bolaños, no es sólo preguntarse por lo desconocido, lo inasible, lo inefable, que buena parte de la historiografía ha querido denominar como una reacción normal, un deducir de un significado el significante (el más asequible). ¿Qué quiere decir esto? Que si bien si se trata de un otro desconocido la potencia del lenguaje es capaz de abstraer un sentido con tal de favorecer con rigidez una definitiva versión de la historia. El otro, es sabido, es el habitante que desde la Grecia antigua legitima, en última instancia, la empresa colonial. El otro debe existir para que exista también el todo: esto claro, es la típica legitimación del más fuerte que, en busca de motivos, encuentra una razón de peso para tener enemigos. Los Pijaos son entonces el pretexto perfecto sin olvidar a los Caribes de la costa norte colombiana- que encuentra Simón para justificar el exterminio y la evangelización española. No sólo porque los nombra como diferentes sino porque los condena a un estereotipo, clásico también: el caníbal.

Las primeras noticias de la empresa en contra de los Pijaos representaron pérdidas considerables en los ejércitos conquistadores. Así que desde 1513 y casi durante sesenta años, las noticias de las bajas españolas eran consideradas imposibles sin que existiera un argumento potente que lo justificara. Así que desde Sebastián de Belalcázar hasta Diego de Bocanegra, los españoles se enfrentaron con un ejército de hombres muy bien capacitados para la guerra y que, muy al contrario de los caníbales y sodomitas, contaban con una inteligencia fundada en su potencial humano. ¿Qué deduce Simón de las crónicas de los ilustrísimos señores de Indias? Que se enfrentaron con la monstruosidad, con hombres que comían carne humana hasta saciarse y que, además, copulaban sin fines procreadores. El pecado quedaba catalogado y así se explicaba cómo, unos hombres sin alma, eran capaces de vencer la empresa de la Santa Iglesia.

Así, un otro se convierte, a través del lenguaje, a través de las cientos de hipérboles de las que lo nutre Simón, en un ser salvaje y violento por naturaleza. De acuerdo con Lyotard, cuando habla de los derechos del otro, por ejemplo, se entiende que esta relación del lenguaje es muy particular. Es una relación en la que queda excluido el otro incluso como sujeto pasivo de la conversación, por no decir de la comunicación pública; El otro será siempre extraño. Me parce recordar que también se sorprende al anotar que los mismos griegos, inventores de la Politeia, privaron de tal privilegio a los bárbaros y deja claro que el otro siempre sobrevuela como una amenaza sobre la identidad de aquello considerado como propio. Como se expuso en la reflexión sobre el otro en Castellanos, es necesario anotar que la definición de ese otro se cristaliza en la palabra escrita expresa.

A partir del texto de Félix Bolaños, puede apreciarse cómo el referente caníbal en la retórica colonial se ficcionaliza de acuerdo con los intereses del discurso imperante. El resultado entonces se convierte en la verdad. En esta discusión sobre el episodio de "la toma de Ibagué" no parece ser importante la veracidad, tan discutida, histórica de los hechos. Lo interesante es captar la versión de Fray Pedro Simón que, entre otras cosas, es el discurso que legitima el exterminio del otro. Como en todas las guerras, a 
lo largo de la historia de occidente, la verdad queda escrita por los ganadores. Así en ese episodio puede verse cómo Simón convierte en héroe a Gaspar Rodríguez y, para entregarle esta facultad, tiene que exagerar el número y la crueldad de sus enemigos: de nuevo, los Pijaos.

Parecía un día de Juicio el alboroto de la plaza y toda la ciudad: aquí sonaban voces, allí gritos de niños y mujeres y muchachos que los daban a sus maridos y padres, acullá gemidos mezclados con voces de caracoles y trompetillas de los bárbaros que discurrían por todas con furia de demonios, pegando fuego a cuanto había. (Simón: 380)

En esta cita está convenientemente involucrado el discurso religioso. El Juicio, los demonios y el fuego, remiten directamente al Apocalipsis. ¿Rodríguez pelea contra el demonio? Este "caballero" se convierte en el instrumento de Dios, de la justicia Divina para extirpar el pecado de la tierra. Simón utiliza los términos que, históricamente, producen una reacción predecible en el lector: se trata de bárbaros, ampliamente conocidos en la literatura clásica, se trata de demonios, se trata, en fin, de cargar un discurso con tal cantidad de referentes, un discurso que desnudo de dichos referentes no valdría más que para contar una querella entre dos bandos.

Es imposible, en una primera lectura, no sentirse escandalizado por las acciones de los indígenas y es difícil no sentir un poco de alivio cuando Dios estira su brazo para acabar con la plaga. Sin embargo, en una lectura más atenta habría que preguntarse, ¿Quiénes son realmente los bárbaros? ¿De quién proviene el fuego de antorchas quemando chozas? Como si la historia hubiese juzgado a los españoles cuando defendieron su legítima propiedad sobre el territorio, expulsando a los árabes de España. ¿Por qué los Pijaos no tenían ese mismo derecho?

\section{El otro visto desde la otredad: Juan Rodríguez Freile}

Juan Rodríguez Freile se confiesa como Neo Granadino a diferencia de Simón y de Castellanos. Es por esto que su escrito está llamado a ser, en mi opinión, la primera noticia de un nuevo mundo visto con los ojos de un criollo que, a pesar de percibirse como español, intenta filtrar un nuevo sesgo en la identidad de las Indias Occidentales. El Carnero incluye por primera vez desde la publicación de las Noticias de Simón y las Elegías de Castellanos, datos del autor, asunto que, además de involucrar afectivamente al escritor, acorta la distancia con que se escribía en las obras anteriores. El texto, sin embargo, contiene dualidades en cuanto a la mirada del indígena. Por una parte hay ciertas referencias que permiten rastrear patrones de identidad en la fundación de Santafé de Bogotá: la descripción de la guerra entre los caciques de Bogotá y Guatavita, los rastros precolombinos, la mención a los rituales de El Dorado, etc.; configuran un tinglado sobre el que Rodríguez Freile se mueve con la libertad suficiente para, entre líneas, decir que el presunto Nuevo Mundo, desde tiempos inmemoriales, también tiene tradiciones. Por la otra, y en esto consiste la ambigüedad del texto, Rodríguez Freile, a causa de razones tan dispares como tener origen judío pero además conseguir el beneplácito de España para su obra, se confiesa 
"cristiano antiguo y fiel a su Majestad el Rey de España". El origen de Rodríguez importa poco si se tiene en cuenta que El Carnero es el primer libro en el que se da cuenta de una serie de patrones de identidad que, a pesar de estar filtrados, contribuyen de manera definitiva, a recoger más pistas sobre la mirada del otro tan repetida en esta reflexión.

La diferencia con las obras anteriores es definitiva. Se abandona el tono épico utilizado por Castellanos y Simón y, más allá de la circularidad de un mito como puede ser el Yurupari, lo que encierra El Carnero es la visión de un mundo privado que, devela el verdadero "estado de las cosas" en la Nueva Granada. Así, el otro aparece en las primeras páginas, como parte de un imaginario vigente pero no definitivo en la construcción de la obra. Después de la crónica de la conquista y de las batallas entre Guatavita y Bogotá, el tono se invierte para adentrarse en "los mundos privados" de la imperante corrupción en Santafé.

La idea moralizante, sin embargo, no escapa a Rodríguez y sus episodios referentes a la creación del mundo parecen más sesgados hacia un afán legitimador de su obra que hacia una verdadera explicación de la concepción del mundo. La ironía se antepone a la moral y la idea del otro se desplaza al territorio de lo erótico y lo político. Para Rodríguez los indígenas son el pasado, el presente está salpicado por la codicia de El Dorado sembrada por Jiménez de Quesada. Ese hecho fundamental marcaría las conciencias que Rodríguez se propone describir.

El Bogotá con los indios de la sabana acudieron al Adelantado Jiménez de Quesada pidiéndole les diese favor y ayuda para cobrar a sus mujeres e hijos; el Adelantado acudió muy bien a estos porque de la gente de los tres generales sacó una buena tropa, con la cual entraron los indios tan a tiempo y en tal ocasión, que cobraron lo que era suyo, quitándoles a los panches lo que tenían [...] Los soldados salieron aprovechados del pillaje de los panches adonde hallaron muy buen oro en polvo. (Rodríguez: 62-63).

Pareciera que en este hecho se funda el imaginario que hasta hoy recorre el mundo occidental: la idea de la abundancia escondida que jamás existió y que se convertiría en estandarte del imaginario colectivo. La idea de dar cuenta de una verdadera historia, la de los adelantados y sus secretos, la de una ciudad que se pretendía tan cerca del oro pero que no ofrecía sino corrupción y laberínticas intrigas.

Es con Rodríguez que se funda también la idea de ciudad. Este Nuevo Mundo, es cierto, ha sido profanado por la conquista y, sin embargo, no ha sido sino con el arribo de las fundaciones que se ha empezado a olvidar. El rescate de Rodríguez es lo que podría nombrarse entre líneas, la historia no oficial. Es por lo mismo que se enfrentan los métodos anteriores a los que se mencionan al comienzo de la obra: "donde faltan letras falta el método historial, y faltando todo eso, falta la memoria de lo pasado" (Rodríguez: 11). Aunque no podría llamarse a El Carnero una obra contestataria, su nivel subversivo la separa de las épicas narraciones de Simón y Castellanos; corresponde en verdad a una visión del otro desde la otredad. Otra vez, la mujer y la historia, son el recurso que, en síntesis, se convierten en el pretexto para adentrarse en los mundos privados, de los americanos, los otros. 
Es un mundo occidental, es un mundo escrito, y si Colón escribe que vio sirenas, las sirenas existen. Si Castellanos escribe que hubo un banquete caníbal, en América hay caníbales. Es una palabra que crea realidades conceptuales, es una escritura que sella el futuro de la nueva tierra, que se presenta como un paraíso, se transforma en una opción de redención para el español y, finalmente, se convierte en la caldera del diablo. La misma realidad, la misma historia, tres discursos consecutivos y una capacidad de destrucción y saqueo nunca antes vista, en nombre de la palabra.

¿Pero cómo podría concluir sin remitirme a los orígenes? Se había dicho al comienzo de este ensayo que se iba a empezar por el principio y que el principio era Castellanos. Si bien es el principio de esta retórica creadora de realidades, existe un paso anterior en la percepción del otro en América, es anterior a las cartas de Cortés y anterior al diario de Colón. Es una percepción que se origina en el mundo que se creía virgen pero que no lo era en absoluto; una percepción del nativo acerca de sí mismo: de la otredad que componían sus realidades espirituales y que en una reflexión como esta es imposible dejar por fuera. Una vez explorada la visión blanca y autorizada del indígena, es pertinente ver cómo él se definía a sí mismo, desde la percepción no oficial. De esta manera puede el lector asomarse al origen de la composición dual a la que pertenece el nativo.

\section{El otro como figura del poder. Yurupari}

"Sólo entonces descubrieron al viejo payé, tranquilamente sentado entre ellas, sin que ninguna pudiera decir ni cuándo ni cómo había llegado". (Stradelli: 182) Esta cita, que aparece en el segundo párrafo del Yurupari, mito fundacional del imaginario del Vaupés, transcrito por Ermanno Stradelli, da cuenta de una de las figuras de poder centrales en el mito y en la imaginación de un otro aborigen poderoso y sobrenatural: el payé. El payé es la piedra angular de toda la cosmogonía del mito; él aparece cuando nadie lo espera y observa a las mujeres mientras discuten la posibilidad de fecundarse unas a otras. Es el otro inasible que desde su silencio ordena el caos imperante. ¿Y acaso el poder puede ejercerse desde el silencio? El payé no es un dios y por lo tanto no es una voz de mando a la manera occidental. Él, en cambio, posee la sabiduría para organizar ${ }^{1}$. ¿Qué organiza? Los posibles desequilibrios que en la mayoría de los casos, de acuerdo con el Yurupari, encarnan las mujeres y la sexualidad exacerbada. Estos desequilibrios deben entenderse leyendo un sistema cosmogónico que nada tiene que ver con el que profesa occidente. Así, por ejemplo, en el caso del episodio descrito, puede decirse que la fecundación no se ejercerse exclusivamente en una dirección.

\footnotetext{
${ }^{1}$ Es importante recordar que en todo caso el texto que conocemos es una recopliación hecho por estudiosos occidentales, y traducido antes, incluso, a otros idiomas antes que al español. Es notable que después de varias líneas, las palabras no pueden dar cuenta de la figura chamánica de una manera precisa y así como el mito -transcrito- intenta recuperar a través de la potencia del lenguaje occidental una concepción contraria a la nuestra, es necesario utilizar comillas para todo eso que no es exacto en la figura encarnada del payé.
} 
Aunque parezca extraño, la figura del chamán transcrita por Stradelli, es el trazo que sugiere que la visión del otro en la concepción occidental tradicional ha tenido que adecuarse a ciertas particularidades, a ciertas reglas, que gravitan sobre el discurso y a ciertos órdenes que, a pesar de ser incomprensibles, han "tratado" de ser traducidos con las herramientas asequibles. El chamán es una figura polémica: de sacerdote a gurú, de brujo a loco, ha sido de algún modo inasible para la concepción occidental del mundo. Stradelli ha tratado, sin embargo, de conservar y de difundir una perspectiva que la antropología ha acogido, esta es, la de organizador social y natural. El chamán coexiste dentro de las familias, no es un ser extraño que vive alejado de la realidad de sus tribus, pero tampoco es lo que comúnmente puede pensarse como cacique o jefe de tribu. A lo largo de todo el mito se sugiere como voz, como presencia; esto porque es de él y no de otra entidad, que depende que se diriman los desequilibrios naturales. En uno de los episodios se anuncia que Pinon fecunda a todas las mujeres en una noche. El payé al enterarse siente ira, sin embargo, como sabe que de él depende su pueblo y, como además encuentra un motivo positivo en el acto de Pinon - la fecundación acrecentará la población y por ende la fortalecerá -, no actúa por prohibición, como en el caso de las mujeres, y permite que Pinon se convierta en un revitalizador-engendrador de los ilapay, convirtiéndolos en mayoría ante sus enemigos los binacas.

De este modo y aunque la figura del chamán siempre aparezca confusa, su función social se clarifica al comprender que más allá de ser "guía espiritual" el chamán es la función reguladora social por excelencia. Su presencia es inaprensible, pero su oficio cada vez más inteligible. Gerardo Reichel Dolmatoff, en su libro Orfebrería y Chamanismo, refiriéndose a la representación de la figura chamánica, ha señalado la dificultad que presenta el tratar de encontrar un sistema que clasifique o dé cuenta de lo que es en realidad el chamán y propone que esa es tal vez la tarea del futuro para los antropólogos e historiadores. Dentro de esas múltiples formas de representación se podrían citar sólo algunas que, más que ser de carácter unívoco, son sólo hipótesis conducidas por la orfebrería hallada en las zonas del Vaupés; clasifica Dolmatoff, cabezas de aves auxiliares, cinturones, colas bifurcadas, chamánes bicéfalos y hasta murciélagos con cara de hombre. Ahora bien, ¿por qué hablar de iconografía cuando se intenta discernir la función social del chamán? Porque el testimonio de Stradelli es tan múltiple como las representaciones que trata de encontrar Dolmatoff en la orfebrería y, de allí que tal vez, en las tribus mismas esa multiplicidad sea en realidad el chamán. El otro poderoso se encarna en ese gran compás que iría desde la interpretación hasta la transcripción.

El Yurupari en particular contiene la idea de un chamán representativo que encarna figuras de la naturaleza pero, además, es el interventor directo en momentos de fisura. No se trata solamente de un consejero o de un organizador, sino de alguien que dispone las relaciones del hombre con el hombre y del hombre con la naturaleza;

Que nadie trate de seducir a la mujer del otro bajo pena de muerte, la cual caerá tanto al hombre como a la mujer. [...] Qué ninguna muchacha que haya llegado al 
momento de ser violada por la luna conserve los cabellos enteros bajo pena de no casarse hasta la edad de los cabellos blancos. (Stradelli: 227)

Así aparecen dos leyes dictadas por Yurupari mientras saca del matiry un poco de cera. La transgresión es un elemento que obliga al payé a estar alerta. Después de dictadas las leyes éstas son infringidas y la función social cada vez se aclara más en el sentido de buscar el equilibrio.

Fue por ese día que apareció el primer payé, y fue en la maloca de Cudiacury, y apenas Pinon supo que existía un hombre que veía todas las cosas a través de la imaginación, se dirigió hacia allí. (Stradelli: 222)

Esta aparición muestra como la iniciación, además de asegurar la transmisión del conocimiento para evitar la constante transgresión femenina, es un ritual que introduce al conocimiento del mundo. El Yurupari está lleno de referencias a la burla de la regla por parte de la mujer que conjura el chamán a través de la imposición de leyes que aseguran el orden.

Ese es el Yurupari en su extensión. La figura de payé siempre será un otro referente a lo que en occidente se llama desconocido. Es un poder múltiple, una fuerza organizadora que representada o no, da pistas sobre esa otredad que hasta nuestros días se plantea aterradora. Para los ilapay la otredad no es otra cosa que el desorden, pero eso que encarnan las mujeres es la otra mitad que debe existir para que el orden también lo haga. Lo que inaugura la noción de chamán es el secreto, el secreto que contiene el orden:

Ahora que ya conocen mi ley, con la cual deben cambiar los usos y las costumbres de esta tierra, que el payé haga respirar el humo de su cigarro a las mujeres que duermen [...] El payé fue desde ese día escuchado y obedecido en todo y por todos. (Stradelli: 255)

\section{A manera de epílogo: de lo mágico a lo maravilloso}

Para terminar, quisiera hacer eco de algunas sugerencias acerca de la posibilidad de rastrear el realismo maravilloso en los textos de los primeros cronistas, puesto que eso daría cierta continuidad al tema tratado, más allá de los primeros asentamientos coloniales en La Nueva Granada. Podría incluso percibirse esa noción de lo no identidad hasta la segunda mitad del siglo XX. Esto es importante porque la noción de lo otro, aunque modificada, sigue apareciendo en relación a los contextos americanos; es interesante, sin embargo, que cinco siglos más tarde, la percepción de aquello extraño rondando por América, no sólo se conserve, sino que el americano, que por definición en este artículo ha sido siempre el otro, sea ahora quien perciba esas realidades americanas como ajenas ${ }^{2}$.

${ }^{2}$ Todavía hoy, incluso en América, vende más un tónico capilar cuyos ingredientes secretos provienen del Amazonas que el de ninguna farmacéutica reconocida. 
Cito a Fray Pedro Simón para enlazar los dos conceptos (la alteridad y el realismo maravilloso) y así explicar la afirmación anterior:

Precedieron también algunas señales pocos días antes de que algunos tomaron por indicación o presagio el suceso: hundióse en el pueblo la capilla mayor de la iglesia y pasaron un día tanta infinidad de mariposas volando por encima del pueblo, cosa nunca vista hasta entonces, que ocultaban el sol. (Simón: 377)

Quisiera explicar por qué utilizo el término realismo maravilloso. Es un término que fue propuesto por Irlemar Chiampi en su libro titulado "El Realismo Maravilloso". En gran medida estoy de acuerdo con las razones que esgrime para justificar la necesidad del neologismo. Sin embargo, me parece que las diferencias entre lo que significan "realismo mágico" y "real maravilloso" se pueden ampliar un poco. Estas diferencias se dan puramente a nivel del lenguaje; en lo que las palabras pueden llegar a significar, y lo que dichas expresiones representarían si se tomaran en un sentido literal. Pero siendo el lenguaje el tema principal de este artículo, no es conveniente ignorarlo.

Empiezo con "realismo mágico". Chiampi no parece comprometerse con alguna definición del término, no obstante, ofrece una cita de la investigadora soviética Vera Kuteishchicova: "Aunque el sentido general de éste término sea inteligible, por lo pronto carece de un contenido nítido." (Chiampi: 31).

Para hacer referencia al lenguaje me tomaré la libertad de elegir, arbitrariamente, como presupuesto una teoría referencial del lenguaje, (la que propone San Agustín). Analizadas bajo otras teorías lingüísticas, las propuestas seguramente quedarían invalidadas, pero la conclusión última de la teoría propuesta es demostrar la insuficiencia del lenguaje; no obstante no ser ese mi objetivo, me interesa la estructura del argumento.

El lenguaje está compuesto de signos que hacen referencia a objetos conocidos sensiblemente. El mundo existe, y existe antes del lenguaje. El hombre lo que hace es nombrar ese mundo. ${ }^{3}$ El sonido de las palabras es tan sólo un efecto acústico que se asocia a una imagen. Por ejemplo: la palabra madre, es un sonido que se asocia a la persona que aparece cuando decimos la palabra madre. Pero debe conocerse de antemano a esa persona, de lo contrario, la palabra no tendría sentido alguno. Es necesario establecer una diferencia entre la palabra y lo que esta significa, dado que la palabra hiere el oído, y el signo excita una imagen en nuestro espíritu; esa imagen es lo que ha dejado lo representado en nuestro espíritu. Esto es, en el caso de madre, existe la palabra, existe lo que entendemos cuando la oímos y existe la persona que responde a ese nombre. Por lo tanto, es imposible que la palabra enseñe algo, dado que debemos conocer a qué se hace referencia de antemano para que cobre significado. De lo contrario, no haría más que herir nuestros oídos. Como el lenguaje

\footnotetext{
${ }^{3}$ En la tradición judeo-cristiana ocurre al contrario, primero existe la palabra y por medio de ésta es que se crea el mundo sensible.
} 
se aprende por el hecho de vincular las cosas que se ven con los efectos acústicos que los mayores usan cuando se refieren a ellos, es imposible que el lenguaje, que es cadena de signos, enseñe algo; o bien recuerda algo que tenemos en la memoria, o bien ilumina algún oscuro seno de nuestros espíritus donde ya existe lo referido, y que ignorábamos que estaba alli $^{4}$. De esto se sigue que el lenguaje sólo se refiere a lo que es, no a lo que no es, puesto que lo que no es, carece de referente. Cuando entendemos el lenguaje, es porque conocemos de antemano los referentes que coordinan con los efectos acústicos de dicho lenguaje.

Por ahora me gustaría señalar qué tanto problema sugiere la definición de "realismo mágico" que propone Vera Kuteishchicova. Teniendo en cuenta que no se puede entender una palabra sin un referente previo existente en la realidad, ¿cómo se podría explicar que se entiende el sentido general del término si carece de un contenido nítido? Es necesario, entonces, otorgarle algo de nitidez a al contenido de la proposición.

Realismo. En la segunda acepción que le otorga a la palabra el Diccionario de la Real Academia de la Lengua Española, significa: "sistema estético que asigna como fin a las obras artísticas o literarias la imitación fiel de la naturaleza". Con respecto a esta palabra, creo que no hay mayor dificultad, más allá de entender que la naturaleza es lo real, siendo lo real "lo que tiene existencia verdadera y efectiva". La siguiente, sin embargo, plantea una posibilidad irracional: lo mágico.

Magia, en su acepción corriente, es el arte o saber que pretende dominar los seres o fuerzas de la naturaleza y producir, a través de ciertas prácticas y fórmulas, efectos contarios a las leyes naturales. (Chiampi: 49)

La magia pretende subvertir los órdenes naturales, conforme lo cual se introduce en los textos como elemento exógeno a la realidad. Esto es, entra de forma violenta en un texto y genera contradicción. Al lector le cuesta trabajo asimilar el suceso, incluso produce reacciones de incredulidad en los personajes de la obra. Para dar un ejemplo, me remitiré a un pasaje de El reino de este mundo:

Cierta vez, la Mamán Loi enmudeció de extraña manera cuando se iba llegando a lo mejor de un relato. Respondiendo a una orden misteriosa, corrió a la cocina, hundiendo los brazos en una olla llena de aceite hirviente. Ti Noel observó que su cara revelaba una tersa indiferencia, y, lo que era más raro, que sus brazos, al ser sacados del aceite, no tenían ampollas ni huellas de quemaduras, a pesar del horroroso sonido de fritura que se había escuchado un poco antes. Como Makandal parecía aceptar el hecho con la más absoluta calma, Ti Noel hizo esfuerzos por ocultar su asombro. (Carpentier, 1995: 21)

${ }^{4}$ Con esta última posibilidad, San Agustín pretende salvar el escollo que presentan las palabras de carácter sagrado, por ejemplo la palabra Dios. 
Esta es una clara intervención de la magia en el texto, es un hecho que desborda los límites de la realidad. La mujer es una bruja y por medio de ciertos poderes altera el curso natural de la realidad. Sin embargo, existe un ámbito dentro del cual eso mágico se convierte en real, quiero decir, que se vuelve natural. ¿Cómo?

Lo maravilloso es un elemento que no ejerce violencia contra la naturaleza. Es algo improbable pero no imposible, es maravilloso porque es inusual y por eso generalmente carece de un efecto acústico propio, de una palabra que lo nombre y lo determine. Las palabras se aprenden por la costumbre de asociar siempre los mismos sonidos a los mismos objetos. Cuando el hombre se enfrenta a lo no cotidiano, el lenguaje se vuelve insuficiente, pues el sujeto carece de las palabras para referirse a "eso"; entonces se ve obligado a dar ejemplos y explicar lo desconocido por medio de lo conocido.

Por otro lado, el lenguaje es informador de cultura, y si no existe palabra para señalar cierto referente extra-lingüístico, es muy probable que esa realidad no esté concebida dentro de la cosmovisión de quienes participan de ese lenguaje. Irlemar Chiampi, menciona el problema al que se enfrentan los conquistadores españoles cuando llegan a América: "La misma crisis lexical del conquistador español, ante la contingencia de tener que nombrar lo nuevo" (Chiampi: 52).

No es de extrañarse, que los conquistadores, hayan encontrado todo "maravilloso", puesto que se estaban exponiendo a realidades desconocidas, pero que no dejaban de ser realidades. No tenían las palabras para designar esos referentes extralingüísticos y, en consecuencia, no comprendían lo que estaban viendo. La comprensión se da sobre la base del lenguaje, porque es el lenguaje el vínculo entre el ser y la realidad externa. Es muy importante resaltar que lo maravilloso es posible. Es entendible, también, que los españoles hayan creído que se encontraban en "las indias", ya que también desconocían los referentes extra-lingüísticos de las lejanas tierras, y como las noticias que tenían de oriente, las obtenían por medio de ejemplos y comparaciones, no tenían un verdadero lenguaje para comprender su error.

Maravilloso es lo 'extraordinario' lo 'insólito', lo que se escapa al curso diario de las cosas y de lo humano [...] es un grado exagerado o inusual de lo humano, una dimensión de belleza, de fuerza o riqueza, en fin, de perfección, que puede ser mirada por los hombres. Así, lo maravilloso preserva algo de lo humano en su esencia. (Chiampi: 54)

Es claro, ahora, porqué para los europeos (por ejemplo), las realidades americanas son maravillosas; pero es curioso que, para los mismos americanos, también lo sean. Es aquí donde la teoría del lenguaje adquiere sentido. Quiero decir con esto, que está bien para quienes no poseen un lenguaje que dé cuenta de lo extralingüístico en América, pero para el americano, que vive eso maravilloso, ¿por qué ha de parecerle maravilloso cuando basta con visitar ciertas regiones para ver el realismo maravilloso en movimiento? Perece ser que la razón de esto radica en el sistema educativo que América ha tenido: el pensamiento occidental y la revolución copernicana. Han sido estos los referentes lingüísticos los que le han legado a América para traducir el 
mundo. Es necesario resaltar que América no padeció una Edad Media, un Renacimiento o una transición a la Modernidad; dicen los más radicales que en América los hombres bajaron de los árboles directamente al ferrocarril.

Desde que el racionalismo decidió explicar toda la realidad por medio de un orden lógico de causas naturales, ciertos referentes extralingüísticos que daban cuenta de cierto tipo de realidades, quedaron sin lenguaje. Me refiero a la religión, al mito. La ciencia ha relegado el mito al ámbito de los cuentos y mentiras, de las fábulas; se ha desprestigiado al punto de crear un vacío espiritual que se pretende llenar con tecnología, con lógica, lo que queda por fuera de las capacidades intelectivas del hombre moderno, es mentira. El mito da cuenta de realidades espirituales trascendentes que ninguna ciencia podrá explicar. Esa es la razón por la cual a la gente educada le parecen maravillosas ciertas experiencias que son naturales para personas de determinada tribu o comunidad que preserve sus creencias míticas. Es por eso que la metamorfosis de Makandal o de Ti Noel dejan de ser mágicas para introducirse en el ámbito de lo maravilloso. Si bien logran esa esas experiencias después de haber sido iniciados y, amparados por cierta magia, el evento es real, porque el mito le confiere esa realidad.

El mito designa una «historia verdadera», y lo que es más, una historia de inapreciable valor, porque es sagrada, ejemplar y significativa $[\ldots]$ el mito tiene $-\mathrm{o}$ ha tenido hasta estos últimos tiempos- «vida», en el sentido de proporcionar modelos a la conducta humana y conferir por eso mismo significación y valor a la existencia. (Eliade: 7-8)

El mito informa la cultura cuando tiene un lenguaje que comprende esas realidades espirituales; y, como es manual de comportamiento, entonces define las acciones de determinada cultura. Las personas de cierta tribu, por ejemplo, van a desenvolverse en el mundo como sus mitos aconsejan y, por lo tanto, el mito valida las acciones de esas personas: dicta el patrón de cómo una cultura aparece frente a su entorno. Para algunas culturas que conservan sus mitos, los referentes extralingüísticos tienen efectos acústicos correspondientes, esto es, que tienen lenguaje. Y es por eso que se vuelven maravillosos los eventos mágicos y se vuelven reales.

Lo real maravilloso, término inventado por Alejo Carpentier y divulgado en el prólogo a su novela El reino de este mundo, se refiere al ambiente mágico atestiguado por cualquier turista que haya asistido al mercado de Chichicastenango en Guatemala o a la ceremonia macumba en Yamanjá en la playa de Copacabana. O sea que la trascripción a la página escrita de ese ambiente mágico arraigado en las culturas indígenas y africanas constituye lo real maravilloso. (Menton)

Para terminar con este epílogo quisiera insistir en que lo maravilloso es improbable pero no imposible, y que generalmente es maravilloso porque carece de un lenguaje que dé cuenta de esos referentes extralingüísticos, puesto que el lenguaje se aprende por costumbre. Espero haber expuesto con claridad la diferencia entre realismo mágico y lo real maravilloso. Es una diferencia, al parecer, netamente 
semántica. Pero en eso consiste la tesis sostenida, en atender a diferencias que surgen desde el lenguaje para arraigarse en la conciencia colectiva y que finalmente se convierten en ideas modificadoras de la realidad. Creo que las novelas que se clasifican bajo cualquiera de los dos géneros, participan tanto de uno como de otro y que ha sido heredado desde el los primeros cronistas hasta los autores americanos del siglo XX. Esto, por supuesto, no es más que una conjetura, sin embargo comparto la definición de Chiampi, que pretende fundir los dos términos para darle una identidad a esa literatura etérea, tan difícil de definir.

Lo único real era la relación entre el hombre y sus dioses, entre el hombre y sus demonios. Lo verdadero era siempre simbólico, y el realismo de la poesía era lo único valedero, aunque fuese ambiguo o por eso mismo: las relaciones entre los dioses y los hombres eran siempre equívocas. La prosa servía sólo para hacer una guía de teléfonos, un prospecto para el funcionamiento de una lavadora o la crónica de una reunión de directorio. (Sábato: 273)

Al convertir lo mágico en maravilloso, se deshace la diferencia que los separa, en un nivel literario pero también en un nivel formal, puesto que los españoles se desenvolvieron en América de acuerdo con la creencia de que esas realidades monstruosas eran aquellas para las que los habían preparado los bestiarios. Es por medio de la literatura, lenguaje irreverente con la lógica, que esos aspectos místicos que se introducen dentro de la cotidianeidad de los personajes en las novelas se introdujeron en los protagonistas de la primera historia conquistadora y colonial americana. Si bien en el pasaje del aceite hirviendo puede verse cómo Ti Noel es sorprendido, vale también mirar cómo Makandal no lo hace. Es un momento muy significativo porque enlaza las dos realidades, la mágica (percepción de Ti Noel), la maravillosa (percepción de Makandal). Es lo mismo que pasa en Cien Años de Soledad con el hielo o con los imanes, que pasan de ser magia a ser maravilla, y finalmente, cuando el lenguaje las asimila como parte de sí, se vuelven cotidianas. Es lo mismo que sucede cuando los cronistas describen las realidades encontradas puesto que se invierten los códigos, ya no es la literatura basándose en la realidad, sino la realidad basándose en la literatura.

Aunque la realidad desconocida supera a los cronistas que intentan describirla, en los libros de caballerías, en la tradición animalística medieval y en las diversas realizaciones de la Historia, es decir en la literatura, tuvieron el modelo para elaborar su verdad, su versión de la realidad encontrada, a la que asociaron leyendas, incertidumbres y aspiraciones de la cultura que provenían. Por lo tanto, del extrañamiento y encantamiento que produce el Nuevo Mundo va emergiendo el lenguaje de lo imaginario. Al fin y al cabo, en la literatura se concentra una manifestación del pensamiento humano que ofrece una forma de conocimiento del mundo. (Cabarcas: 42-43) 


\section{BIBLIOGRAFÍA}

Bolaños, Álvaro Félix.

1994 Barbarie y canibalismo en la retórica colonial. Bogotá: CEREC.

CABARCAS ANTEQUERA, Hernando.

1994 Bestiario del Nuevo Reino de Granada. La imaginación animalística medieval y la descripción literaria de la naturaleza americana. Bogotá: Instituto Caro y Cuervo-Colcultura.

CARPENTIER, Alejo.

1992 El siglo de las luces. Barcelona: Seix Barral.

1995 El reino de este mundo. Barcelona: Seix Barral.

CASTEllanos, Juan de.

1997 Elegías de Varones Ilustres de Indias. Bucaramanga: Gerardo Rivas Moreno.

CHIAMPI, Irlemar.

1983 El Realismo Maravilloso. Caracas: Monte Ávila.

ELIADE, Mircea.

1991 Mito y Realidad. Barcelona: Labor.

GARCÍA MÁRQUEZ, Gabriel.

1967 Cien años de Soledad. Bogotá: Oveja Negra.

MENTON, Seymour.

1994 "El realismo mágico en la pintura y la literatura de tres continentes: 1918-1970”, Cuarta cátedra internacional de arte Luis-Ángel Arango, Bogotá, 1994.

RODRÍGUEZ FREILE, Juan.

1997 El Carnero. Bogotá: Instituto Caro y Cuervo.

SiMÓN, Fray Pedro.

1882 Noticias historiales de las conquistas de Tierra Firme en las Indias occidentales. Bogotá: Medardo Rivas.

SÁBATO, Ernesto.

1973 Abaddón, El Exterminador. Buenos Aires: Sudamericana.

STRADELLI, Ermanno.

1983 Yurupary, mito, leyenda y epopeya del Vaupés. Trad. Susana Salesi. Bogotá: Instituto Caro y Cuervo. 